Oikos 117: 1444-1452, 2008

doi: $10.1111 / j .2008 .0030-1299.16651 . x$,

(C) The Authors 2008. Journal compilation (C) Oikos 2008

Subject Editor: Heikki Setälä. Accepted 28 March 2008

\title{
Dynamics of grazing lawn formation: an experimental test of the role of scale-dependent processes
}

\author{
Joris P. G. M. Cromsigt and Han Olff \\ J. P. G. M. Cromsigt (jcromsigt@hotmail.com) and H. Olff, Community and Conservation Ecology Group, Centre for Ecological and \\ Evolutionary Studies, Univ. of Groningen, PO Box 14, NL-9750 AA Haren, the Netherlands. Present address for JPGMC: Mammal Research \\ Inst., ul. Waszkiewicza 1c, PL-17-230 Bialowieza, Poland.
}

\begin{abstract}
Grazing lawns are characteristic for African savanna grasslands, standing out as intensely grazed patches of stoloniferous grazing-tolerant grass species. Grazing lawn development has been associated with grazing and increased nutrient input by large migratory herds. However, we argue that in systems without mass migrations disturbances, other than direct grazing, drive lawn development. Such disturbances, e.g. termite activity or megaherbivore middens, also increase nutrient input and keep the bunch vegetation down for a prolonged time period. However, field observations show that not all such disturbances lead to grazing lawns. We hypothesize that the initial disturbance has to be of a minimal threshold spatial scale, for grazing intensity to be high enough to induce lawn formation. We experimentally tested this idea in natural tall savanna grassland. We mowed different-sized plots to simulate initial disturbances of different scales (six times during one year) and applied fertilizer to half of the plots during two years to simulate increased nutrient input by herbivores or termite activity. Allowing grazing by naturally occurring herbivores, we followed the vegetation development over more than three years. Grazing kept bunch grass short in coarser, fertilized plots, while grasses grew out toward their initial height in fine-scale and unfertilized plots. Moreover, lawn grasses strongly increased in cover in plots with an increased nutrient input but only after coarser scale disturbance. These results support our hypothesis that an increased nutrient input in combination with grazing indeed induces grazing lawn formation, but only above a threshold scale of the initial disturbance. Our results provide an alternative mechanism for the development of grazing lawns in systems that lack mass migrating herds. Moreover, it gives a new spatial dimension to the processes behind grazing lawn development, and hence help to understand how herbivores might create and maintain spatial heterogeneity in grassland systems.
\end{abstract}

The grazing lawn concept was first formulated in the early 1970s (Bell 1971), after which McNaughton (1984) further defined it as the co-evolution between herds of grazing animals and unique communities of grazing-tolerant grass species. Central to this concept is the positive feedback between grazing and the availability of the grass resource. Grazers can increase both the quality of their food by enhancing the nitrogen content of the grasses they graze (McNaughton 1979, Coppock et al. 1983a, Detling and Painter 1983, Ruess et al. 1983) and the availability of their food by accelerating primary production of the grazed vegetation (McNaughton 1976, Cargill and Jefferies 1984, Hik and Jefferies 1990, McNaughton et al. 1997, Ruess et al. 1997). This positive consumer-resource feedback results in intensely grazed patches, i.e. grazing lawns, existing of a characteristic community of grazing-tolerant, short stoloniferous grass species with higher nutrient quality and productivity than surrounding tall, bunch grass communities (Augustine and McNaughton 1998, Archibald et al. 2005). Both lawn and bunch communities form characteristic lawn-bunch mosaics where individual lawn patches vary between several square meters and few hectares in southern African reserves (Owen-Smith 2004, Grant and Scholes 2006) to tens of kilometers in the Serengeti ecosystem (McNaughton 1984).

The importance of grazing lawns for herbivore populations is widely recognized in systems ranging from tropical savannas to arctic tundra (Bell 1971, Coppock et al. 1983b, McNaughton 1984, Person et al. 2003). These studies generally focused on the role of lawns in the temporal dynamics of herbivore populations, showing how grazing lawns might increase long-term population density (Person et al. 2003). However, lawn-bunch mosaics are also a critical component of spatial heterogeneity of food resources in African savanna grasslands (Wilmshurst et al. 1999, Owen-Smith 2004). An increasing number of studies show that spatial resource heterogeneity might buffer herbivore population dynamics against temporal variation in resources (Fryxell et al. 2005, Wang et al. 2006). In addition, such heterogeneity might also mediate resource partitioning among large grazers (Ritchie and Olff 1999, Cromsigt and Olff 2006) and hence contribute to their coexistence. 
Indeed, Cromsigt and Olff (2006) showed experimentally that variation in the size of short grass patches can promote spatial resource partitioning amongst large African grazers. While the importance of grazing lawns for large herbivore communities is increasingly recognized, we know much less about the mechanisms and conditions that create them.

In the east-African systems grazing lawns are associated with large migratory herds of grazing animals. The high grazing disturbance of these herds may prevent bunch grasses from out shading the shorter lawn species, and hence facilitate their invasion (Huisman and Olff 1998). Secondly, the increased nutrient input through the mass urinating of the migratory herds might induce lawn formation because it allows lawn grasses to show compensatory growth in response to grazing in contrast to bunch grass species (McNaughton 1983b, Ruess and McNaughton 1984, Day and Detling 1990). However, large migratory herds are absent in many southern African systems, but in some of these systems grazing lawns are abundant (OwenSmith 1988). We argue that disturbances, other than direct grazing, play a major role in the creation of grazing lawns in these systems. On the local-scale of grassland mosaic formation we can identify fine-scale disturbances, such as small termite mounds, and more coarse scale disturbances, such as middens and wallows that are typically created by megaherbivores, like white and black rhino or hippo (Owen-Smith 1988, Cumming and Cumming 2003, Hobbs and Searle 2005, Mobaek et al. 2005). Both fine and coarse scale disturbances open up the bunch grassland and for a prolonged period of time keep the bunch grass vegetation short (Fig. 1). Moreover, an increased nutrient availability is typical for both disturbances; an increased soil nutrient turnover in case of termites (Jones 1990) and increased urine and dung input in case of megaherbivore middens and wallows (Owen-Smith 1988). Therefore a disturbance of bunch grass vegetation combined with an increased nutrient input might favour invasion by lawn species in the non-migratory southern African savanna systems. However, field observations show that these conditions do not necessarily lead to lawn development (pers.obs.). We argue that current theory on lawn development lacks a spatial component and that the spatial scale of the initial disturbance plays an important role.

Recent ideas that describe the role of self-organized patchiness in vegetation pattern formation (HillerisLambers et al. 2001, Rietkerk et al. 2004) provide a useful framework for thinking about how lawn formation depends on the scale of a disturbance. These studies suggest that the crucial positive feedback between consumers and resources that underlies shifts in vegetation patterns is scale-dependent. We hypothesize that such a scale-dependent consumer-resource feedback plays an important role in grazing lawn formation. Cromsigt and Olff (2006) showed that grazing pressure disproportionately increases with coarser scale distribution of short grass patches (less fragmented). Following this result, we suggest that an increased nutrient input in combination with grazing induces grazing lawn formation, but only after an initial disturbance coarser than a certain threshold spatial scale to attract high enough grazing pressure. Only after such a disturbance grazers keep the bunch grass short for a long enough period of time to allow lawn grass species to invade.

We tested this idea in a natural savanna grassland in Hluhluwe-iMfolozi Park (HiP), South Africa, and set up a full factorial experiment with variation in the scale of disturbance and nutrient input. In grassland dominated by tall bunch grass communities we mowed different sized plots to simulate initial disturbances of different scales and applied fertilizer to half of the mowed plots to simulate nutrient input through dung and urine deposition or termite activity. Allowing grazing by the diverse, naturally occurring herbivore community, we followed the vegetation development over more than three years to see whether an increased nutrient input induced lawn formation and to what extent this process depended on the spatial scale of disturbed patches.

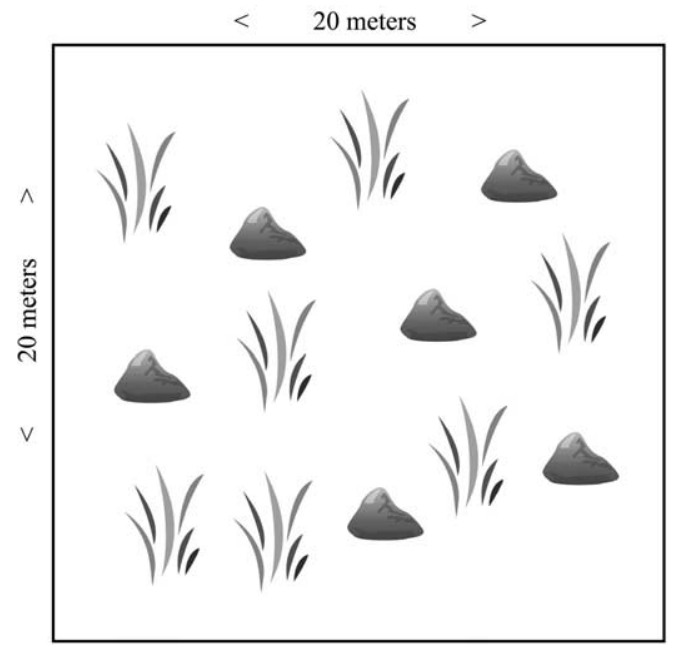

Fine-scale disturbance (termite mounds)

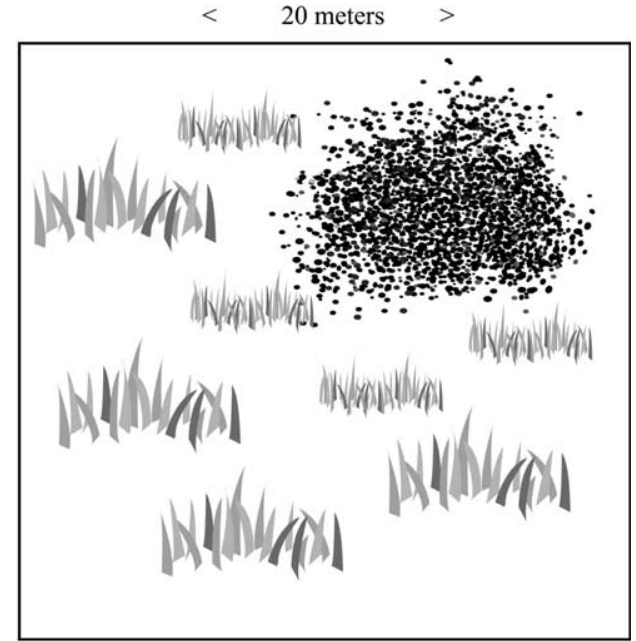

Coarse-scale disturbance (rhino midden)

Figure 1. Examples of fine scale (small termite mounds on the left-hand side) and coarse scale (rhino midden) disturbances in savanna grassland systems. The disturbances are characterized by locally opening up the bunch grass vegetation and increased nutrient input. Grazing intensity, however, is too low in the fine scale disturbance plots to keep bunch grass short, in contrast with the coarser scale disturbance, where bunch grass is kept short around the disturbance. 


\section{Methods}

\section{Study site}

Hluhluwe-iMfolozi Park (HiP) is a small (90 000 ha) but diverse protected area in Kwazulu-Natal, South Africa, situated in the southern African savanna biome, with vegetation types ranging from open grasslands to closed Acacia and broad-leaved woodlands (Whateley and Porter 1983). The mean annual rainfall depends on altitude, ranging from $985 \mathrm{~mm}$ in the high altitude regions to $650 \mathrm{~mm}$ in the lower areas and mainly falls between October and March. Daily maximum temperatures range from $13^{\circ} \mathrm{C}$ to $35^{\circ} \mathrm{C}$. The reserve is of strong conservation importance because it hosts a rich and complete set of indigenous large herbivores and carnivores.

The park is characterized by highly heterogeneous grasslands, in which tall bunch grass (tussock forming) communities of Sporobolus pyramidalis, Eragrostis curvula and Themeda triandra are interspersed with short lawnforming (stoloniferous) communities of Digitaria longiflora, Urochloa mosambicensis, Dactyloctenium australe and Sporobolus nitens. Grazing lawns typically are in the size range between few square meters to maximum 1-2 ha. In HiP, grazing lawns are important because they support high numbers and a high diversity of grazer species ( $>40$ grazers $\mathrm{km}^{-2}$ of six species).

\section{Experimental design}

In 2000 we used a lawnmower to create initial disturbances in the form of different-sized short grass patches in tall savanna grassland, dominated by the bunch grasses Eragrostis curvula, Panicum maximum and Sporobolus pyramidalis with bush encroachment of Dichrostachys cinerea, Acacia spp. and Gymnosporia senegalensis. We created short grass patches at a height of around $5 \mathrm{~cm}$, in contrast with the surrounding tall grass matrix of around $25 \mathrm{~cm}$. Just after our first mowing treatment the region surrounding the experiment and the experiment itself were burnt. Burning was relatively even across the whole area with no difference between treatments and ensured high herbivore visitation at the start of the experiment. The experimental layout consisted of short grass patches of different size in adjacent $8 \times 8 \mathrm{~m}$ treatment plots; $1 \times 1,2 \times 2,4 \times 4$ and $8 \times 8 \mathrm{~m}$ (Fig. 2). We created nine $1 \times 1 \mathrm{~m}$, four $2 \times 2 \mathrm{~m}$, two $4 \times 4 \mathrm{~m}$ and one $8 \times 8 \mathrm{~m}$ subplots per treatment plot to simulate initial disturbances at different scales (Fig. 1). The mowing disturbance treatment was applied during one year (in total six mowing treatments). To simulate increased nutrient input by biotic agents such as herbivores or termites, we applied slow-release NPK-fertilizer four times a year to half of the mown plots. To patches of all sizes we applied 12 gram N, 3.9 gram $P, 19.8$ gram $K, 22.1$ gram $\mathrm{Ca}$ and 18.8 gram $\mathrm{S}$ per $\mathrm{m}^{2}$ of short grass per year. The fertilization treatment was applied for about two years. Each combination of scale of initial disturbance and fertilization treatment was replicated four times. This resulted in $328 \times 8 \mathrm{~m}$ treatment plots (Fig. 2). Surrounding the 32 treatment plots we created eight control plots of $1 \times 1$ meter to test whether vegetation changes could be attributed to grazing.

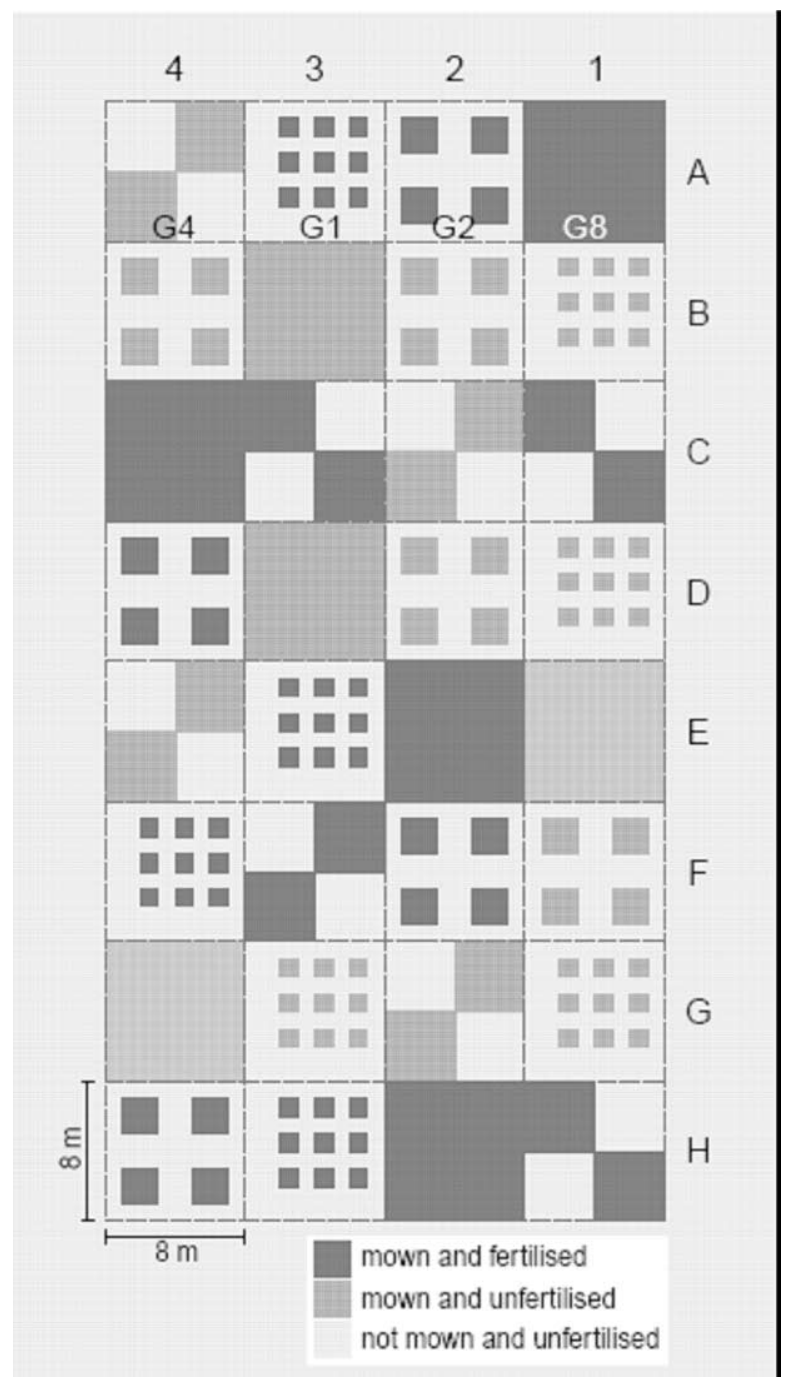

Figure 2. The experimental layout, existing of $8 \times 8$ meter treatment plots with a combination of two treatments (scale of initial disturbance and fertilizer application). Manipulated patches are shown in black and grey; the shaded background represents the untreated matrix of tall grass and shrubs. Half of the plots were fertilized (black) and the other half remained unfertilized (grey). Within each $8 \times 8 \mathrm{~m}$ plot, we created four different scales of initial disturbance in the form of mown short grass patches: nine patches of $1 \times 1 \mathrm{~m}(\mathrm{G} 1)$, four patches of $2 \times 2 \mathrm{~m}(\mathrm{G} 2)$, two patches of $4 \times 4$ meter patches (G4) and one patch of $8 \times 8$ meter (G8).

These control plots were covered by a cage of chicken mesh to exclude all mammalian herbivores. Half of these plots were fertilized. The control plots were mown and fertilized at the same time and in the same way as the 32 treatment plots. Because the control plots were protected from grazing we will refer to them as ungrazed plots, compared with the mown grazed (treatment) plots and the not mown but potentially grazed matrix vegetation. We measured vegetation characteristics to study how scale of initial disturbance and fertilization treatment affected the grazing - vegetation feedback after we stopped the initial mowing disturbance. At the end of the experiment, September 2004, the study area was burnt again and following this burning we stopped monitoring the vegetation. 


\section{Vegetation characterization}

Once a month we measured the height of the vegetation with a round disc of $46 \mathrm{~cm}$ width and a weight of approximately 460 grams. The disc, with a hole in the middle, was dropped along a pole with a height scale in $\mathrm{cm}$. The height was measured to the nearest $\mathrm{cm}$ at 1 point in the middle of the $1 \times 1 \mathrm{~m}$ (also in the control plots) and $2 \times 2 \mathrm{~m}$ subplots. In the $4 \times 4 \mathrm{~m}$ and $8 \times 8 \mathrm{~m}$ subplots the vegetation height was measured in a grid of points one $m$ apart and one $\mathrm{m}$ from the edge of the patch, resulting in nine and 49 points for the two treatments respectively.

We determined the species composition of all the treatment plots in January 2001 and July 2004 within $2 \times 2$ $\mathrm{m}$ quadrates in the middle of each plot. We identified all grass species and estimated their percentage projected cover visually using the Londo scale (Londo 1976). For the $4 \times 4$ $\mathrm{m}$ and $2 \times 2 \mathrm{~m}$ treatment plots, the quadrat was placed in the same subplot for both years. For the $1 \times 1 \mathrm{~m}$ treatment plots, four subplots were selected (the same ones for both years) to get a total survey area of $2 \times 2 \mathrm{~m}$. We identified species and estimated their cover for each of the four subplots and averaged the four cover estimates per species before further analysis. Using the same method, we also measured the species composition in the control plots and in the matrix. For the matrix we measured the species composition in the $2 \times 2 \mathrm{~m}$ matrix subplots in A4, C1, F3 and G2 (Fig. 2), where the same subplots were measured in both years.

\section{Animal visitation}

We directly observed the visitation of different grazer species to the different treatments. The experimental site was situated on a hill slope. From the opposite hillside (about $450 \mathrm{~m}$ from the experiment) there was an open view on the experimental site. From October 2000 up to November 2002, we observed for a total of 903 h during separate 3-h observation periods. For each observation every minute the position of the animal was recorded (according to the grid of $8 \times 8 \mathrm{~m}$ cells shown in Fig. 2) together with the species and its behaviour. Behaviour was separated in two classes: grazing and other. For a full description of the methods see Cromsigt and Olff (2006).

\section{Soil parameters}

We took soil samples in the treatment plots as well as in the surrounding matrix in November 2004 to test if there were any long-term treatment effects on the soil. Per treatment plot five samples were taken randomly distributed over the mown subplots and five were taken randomly distributed in the surrounding matrix of each treatment plot. Samples were taken with a $5 \mathrm{~cm}$ diameter soil core from the upper $10 \mathrm{~cm}$ of the soil and dried at $105^{\circ} \mathrm{C}$. The five samples were pooled and one mixed sample was taken to the lab for the treatment plots and matrix separately, resulting in 64 samples. We ground the samples and analyzed them for total $\mathrm{C}$ and total $\mathrm{N}$ (using the Dumas dry combustion method), texture in three fractions (clay, silt and sand), electric conductivity (EC), $\mathrm{pH}$ (using a KCL solution) and extractable concentrations of $\mathrm{Na}, \mathrm{Ca}, \mathrm{Mg}$ and $\mathrm{K}$. For a detailed description of the used methods see Manson and Roberts (2000).

\section{Data analysis}

\section{Vegetation development}

We first aggregated the vegetation height data as the average of the pseudo replicates per $8 \times 8 \mathrm{~m}$ treatment plot per measuring date. These averages were again aggregated as the average per treatment plot per season per year, dividing a year in four seasons; late wet (lw, January to March), early dry (ed, April to June), late dry (ld, July to September) and early wet (ew, October to December). These season classes were based on long-term rainfall data that are available for Hluhluwe-iMfolozi Park.

First of all, we tested whether change in vegetation height could be attributed to grazing and not to some other factor that was not related to our treatments. For this purpose we compared the height development over time in the ungrazed control plots with our grazed treatment plots. The ungrazed plots only had one size $(1 \times 1 \mathrm{~m})$ and we, therefore, only included our $1 \times 1 \mathrm{~m}$ treatment plots in this analysis. We used a univariate analysis of variance with the factor grazing and fertilization. Time (season periods numbered chronologically) was included as a covariate in this model to account for the fact that height showed a long-term increase over the course of the experiment.

Subsequently, we excluded the ungrazed control plots to test our hypothesis that vegetation height development in the grazed experimental plots should depend on scale of initial disturbance and fertilization. We used a univariate analysis of variance with fertilization and scale of disturbance as fixed factors. Again we included season as a covariate in the model.

Finally, we tested how invasion of lawn grass species depended on the scale of initial disturbance and fertilisation. Before further analysis we divided the observed grass species in each plot into the two functional types; stoloniferous, lawn-forming species and bunch grass species. Three lawn-forming species were observed in the experiment; Digitaria longiflora, Dactyloctenium australe and Sporobolus nitens. For each treatment plot and for the matrix and control plots we summed the \% cover of all lawn species to a percentage lawn cover for each plot. Using a univariate analysis of variance, we tested how year, fertilization and scale of initial disturbance (as fixed factors) affected the total cover of lawn grasses. In this analysis we included the matrix and control plots as a level in the fixed factor scale of disturbance to see if the change in lawn grass cover could be due to another factor that was unrelated to our fertilisation and scale of disturbance treatments.

\section{Total grazing pressure}

Before further analysis we aggregated the total number of observed grazing minutes as the sum of observed grazing minutes over all herbivore species per $8 \times 8 \mathrm{~m}$ treatment plot. A detailed analysis per species is presented by Cromsigt and Olff (2006). We calculated grazing pressure per square meter by dividing the aggregated sum of grazing minutes per plot by the total area of short grass in a plot $(9$, 16,32 or $64 \mathrm{~m}^{2}$ ). Finally we calculated an average observed 
grazing pressure per week by dividing the minutes per square meter per plot by the total of 903 observation hours and multiplying these values with $168 \mathrm{~h}$ in a week. First, we tested how scale of disturbance and fertilization affected grazing pressure using a two-way ANOVA with fertilization and scale of disturbance as fixed factors. Then, we tested whether a possible generic effect of scale of disturbance $\left(1,4,16\right.$ or $\left.64 \mathrm{~m}^{2}\right)$ on grazing pressure depended on fertilization using a univariate analysis of variance with the logarithm of patch size as a covariate and fertilization as a fixed factor. The log of patch size was used to make the distance between patch sizes equal and allow a linear regression between grazing pressure and log (size).

\section{Soil parameters}

We tested for an effect of treatments on all soil parameters using a univariate analysis of variance with the fixed factors, scale of disturbance and fertilization. To test whether soil parameter values differed between matrix and experimental plots we divided the data in three groups; matrix, unfertilized mown plots, fertilized mown plots. Using a one-way analysis of variance followed by student-Newman-Keuls a posteriori contrasts we tested for differences between these groups.

\section{Results}

\section{Vegetation development}

The temporal dynamics in vegetation height could indeed be attributed to the presence of grazers. Vegetation height increased more in the ungrazed control plots than in the potentially grazed treatment plots (Fig. 3, interaction grazing $\times$ time, $\left.\mathrm{F}_{1,554}=65.795, \mathrm{p}<0.001\right)$.

Vegetation height in the grazed treatment plots increased faster in the unfertilized plots than in the fertilized plots (interaction fertilization $\times$ time, $\mathrm{F}_{1,435}=14.155, \mathrm{p}<0.001$ ). Furthermore height increased more in the $1 \times 1 \mathrm{~m}$ patches than in the larger patch sizes (interaction size $\times$ time, $\mathrm{F}_{3,435}=3.837, \mathrm{p}=0.01$ ). The effect of scale of initial disturbance also depended on fertilization (interaction fertilization $\times$ size, $F_{3,435}=8.329, p<0.001$, Fig. 4 shows student-Newman-Keuls a posteriori results). We included patch size as a covariate in the analysis of variance model to test for the generic effect of patch size, with fertilization as a fixed factor, (Fig. 4). Vegetation height decreased with increasing patch size in the fertilized plots, while the height was constant for the different sizes in the unfertilized plots (interaction fertilization $\times \log \left(\right.$ size),$F_{2,445}=12.856$, $\mathrm{p}<0.001$, we log-transformed patch size to allow for a linear regression).

The effect of the scale of disturbance on cover of lawn grasses depended on the year (Fig. 5 , interaction size $\times$ year, $\left.\mathrm{F}_{5,66}=7.354, \mathrm{p}<0.001\right)$. In 2001 there was no difference in the cover of lawn grass between the different scales of disturbance (including the matrix and control) and the cover was close to 0 for all these treatments (Fig. 5A). In 2004 the cover of lawn grasses had increased in the $8 \times 8 \mathrm{~m}$ plots with respect to the other scales of disturbance (including the matrix and control) (Fig. 5B). The effect of scale of initial disturbance on cover of lawn grass also

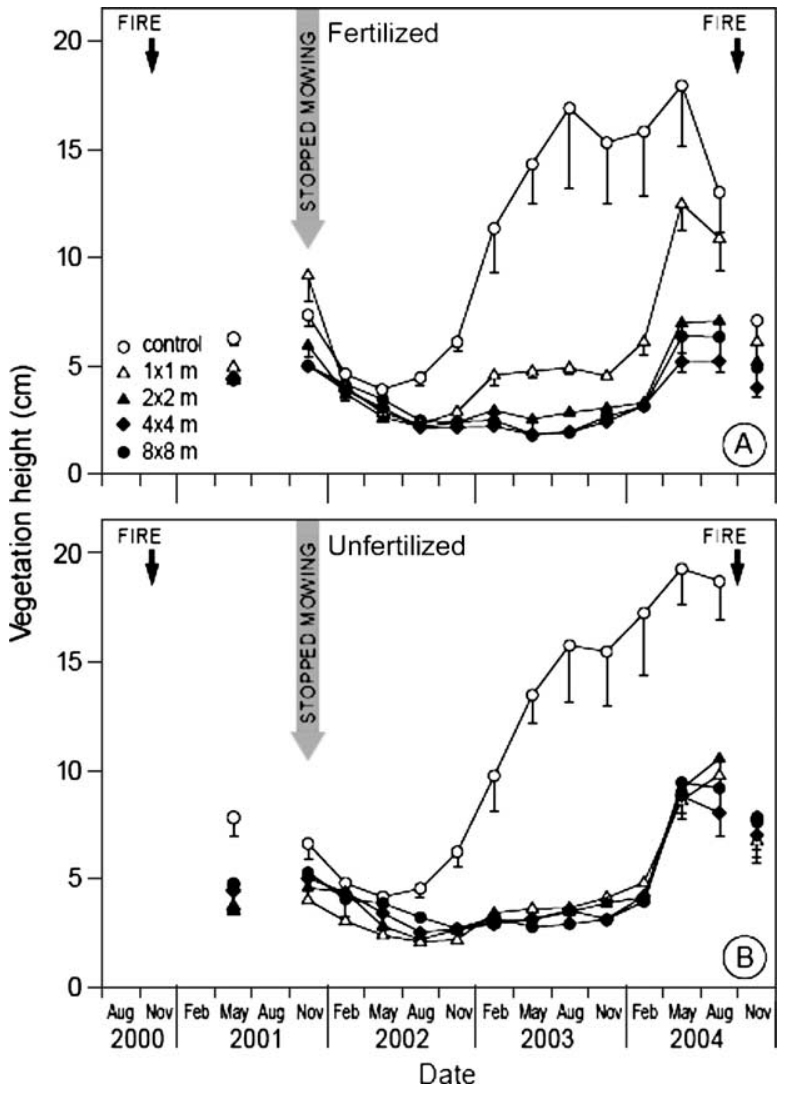

Figure 3. Mean vegetation height ( $-1 \mathrm{SE}$ ) over time for fertilized (A) and unfertilized (B) plots and different scales of initial disturbance, including control plots that were protected from grazing. Height data is aggregated as the average per treatment per season per year, according to the seasons that are explained in the methods section. The experiment was burnt just after it was created, half a year before we started height measurements and once again at the end of the experiment before our final height measurement.

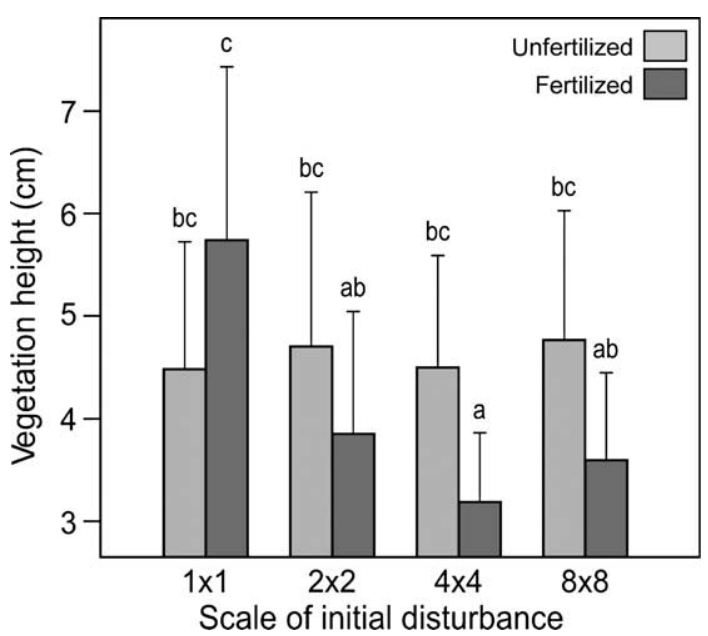

Figure 4. Mean vegetation height ( $+1 \mathrm{SE})$ for different scales of initial disturbance and fertilizer application treatments (Fig. 2). Different letters indicate a significant difference between treatments $(\mathrm{p}<0.05$, student-Newman-Keuls test after one way analysis of variance). 


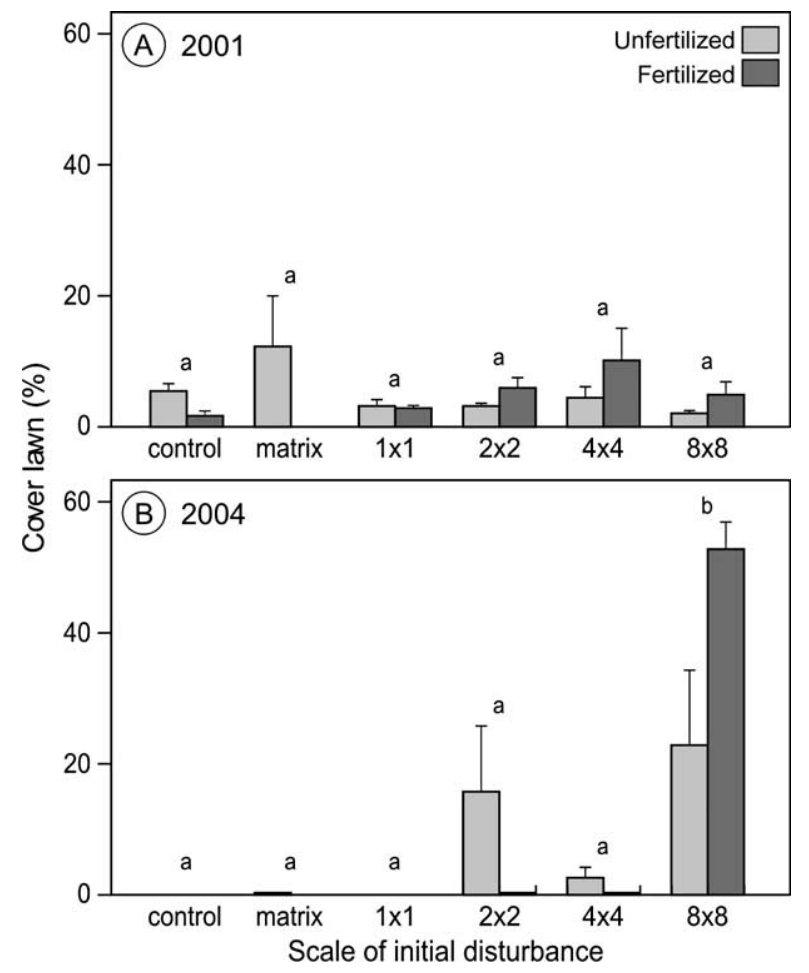

Figure 5. Mean percentage cover $(+1 \mathrm{SE})$ of lawn grass species in the control plots, the matrix vegetation and the different scales of initial disturbance and fertilizer application treatments. In the matrix vegetation we did not have fertilized plots. The results are shown for 2001 (A) and 2004 (B). Different letters indicate a significant difference between treatments $(p<0.05$, student-Newman-Keuls test after two-way analysis of variance).

seemed to depend on fertilization, but this interaction was not significant (interaction fertilization $\times$ size, $F_{4,66}=$ $2.197, \mathrm{p}=0.079$, Fig. 5B). For the 2004 data we therefore included $\log$ (patch size) as a covariate in the analysis of variance model to test if the generic effect of patch size depended on fertilization. In 2004 the increase in lawn cover with increasing patch size was indeed larger in the fertilized plots than in the unfertilized plots (interaction fertilization $\times \log ($ size $\left.), F_{2,29}=6.898, \mathrm{p}=0.004\right)$.

\section{Total grazing pressure}

The following herbivore species were observed grazing in the short subplots (within brackets the number of grazing minutes for the species as a $\%$ of total observed grazing minutes); warthog (Phacochoerus africanus, 50\%), impala (Aepyceros melampus, 33\%), plains zebra (Equus quagga, $12.3 \%$ ), white rhino (Ceratotherium simum, 1.9\%), nyala (Tragelaphus angasii, 1.9\%), wildebeest (Connochaetes taurinus, $0.4 \%$ ), buffalo (Syncerus caffer, 0.3\%) and waterbuck (Kobus ellipsiprymnus, 0.2\%). Grazing pressure was higher in the fertilized $8 \times 8 \mathrm{~m}$ plots than in any other treatment (Fig. 6, interaction fertilization $\times$ size; $\mathrm{F}_{3,24}=3.073, \mathrm{p}<$ 0.047). Total grazing pressure of all species together increased with increasing scale of disturbance in the fertilized plots in contrast with the unfertilized plots where it remained constant (Fig. 6, interaction fertilization $\times \log$ (size); $\mathrm{F}_{2,29}=18.665, \mathrm{p}<0.001, \log$ (size) as covariate).

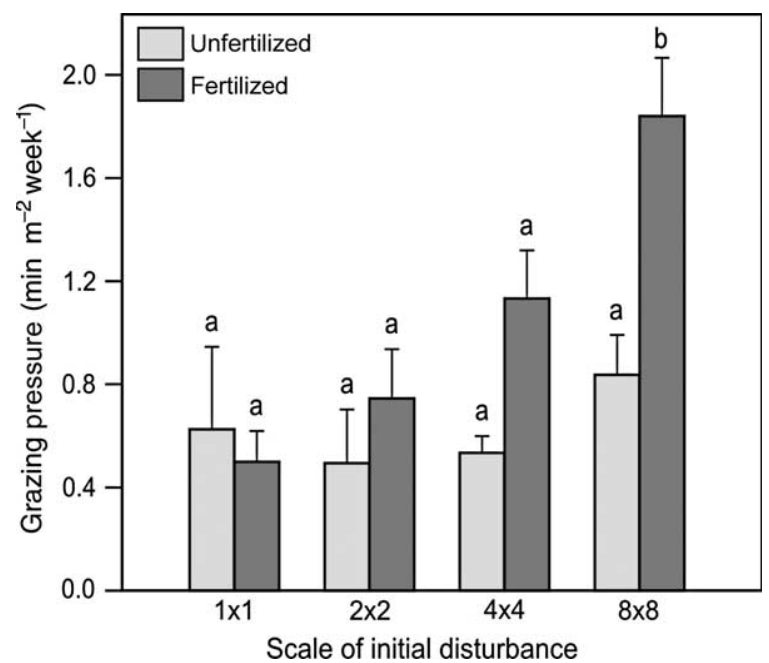

Figure 6. Grazing pressure ( $+1 \mathrm{SE})$ for different scales of initial disturbance (Fig. 2) and fertilizer application treatments. Different letters indicate a significant difference between treatments $(\mathrm{p}<$ 0.05 , student-Newman-Keuls test after one-way analysis of variance).

\section{Soil parameters}

The fertilized plots had a higher electrical conductivity (EC) than the unfertilized plots $\left(\mathrm{F}_{1,24}=8.395, \mathrm{p}=0.008\right)$, as well as higher concentration of extractable $\mathrm{Ca}\left(\mathrm{F}_{1,24}=\right.$ 8.585, $\mathrm{p}<0.01), \mathrm{Mg}\left(\mathrm{F}_{1,24}=5.463, \mathrm{p}=0.028\right)$ and $\mathrm{K}$ $\left(\mathrm{F}_{1,24}=25.542, \mathrm{p}<0.001\right)$. The $\mathrm{pH}$ was significantly lower in the fertilized plots than in the unfertilized plots $\left(F_{1,24}=5.177, p=0.032\right)$. The soil of the matrix vegetation did not differ from the mown unfertilized plots $(p>0.05)$, except for the potassium concentration. The soil concentration of $\mathrm{K}$ was higher in the matrix than in the unfertilized mown plots, but lower than in the fertilized mown plots $\left(\mathrm{F}_{2,61}=12.377, \mathrm{p}<0.001\right)$. Total $\mathrm{C}$ and $\mathrm{N}$ content of the soil, soil texture and soil sodium concentration were not significantly different between any of the size and fertilization treatments $(\mathrm{p}>0.1)$.

\section{Discussion}

As hypothesized, enhanced nutrient availability induced the formation of grazing lawns, but only above a certain threshold scale of initial disturbance. After we stopped mowing the vegetation height started increasing, but the amplitude of this increase depended on whether the plots were grazed and on the scale of the initial disturbance and nutrient status of the plots. The height increased faster in the unfertilized plots with finer scale. Grazing seemed to keep grass short at grazing lawn level in the coarser, fertilized plots $(4 \times 4$ and $8 \times 8 \mathrm{~m})$. Two and a half years after we had stopped mowing a shift in grass community composition had taken place in the least-fragmented fertilized plots, showing a strong increase in the cover of lawn species. Overall grazing pressure was also significantly higher in those plots. In conclusion, the results support our hypothesis that the positive feedback between grazing and 
grazing lawn development depends on nutrient status as well as the scale of disturbed patches.

Hence, disturbances, other than direct grazing, that open up and maintain the bunch grassland in a short state and cause an increased nutrient input might play an important role in the development of grazing lawns in systems that lack large migratory herds of grazing animals. As an example of such disturbances in natural savanna grasslands, we chose two contrasting disturbance types to illustrate our hypothesis (small-scale termite mounds versus coarsescale rhino middens, Fig. 1). In reality there are many more disturbance types that could possibly replace or complement our examples. Large termite mounds, for example, could play the same role as megaherbivore middens or wallows. In fact, studies indicated the role of these large mounds as grazing hotspots (Holdo and McDowell 2004, Mobaek et al. 2005). More studies are needed that quantify these small-scale disturbances in savanna grasslands to get better insight in the processes that drive grazing lawn formation. Our results suggest that the spatial scale of the initial disturbance is an important characteristic that should be taken into account.

We showed that colonization of stoloniferous lawn grass species was the clearest in the fertilized $8 \times 8 \mathrm{~m}$ plots (Fig. 5B), where grazing pressure increased most strongly (Fig. 6). This result supports the idea that lawn grasses can colonize under circumstances of high nutrient availability in combination with a high grazing pressure because these grasses show compensatory growth in response to grazing in contrast with the grazing sensitive bunch species (McNaughton 1983b, Augustine and McNaughton 1998). The evolution of grazing tolerance in grass species is still under debate. It has been attributed to convergent selection processes to cope with drought, which results in traits that also make plants more tolerant to grazing, e.g. basal meristems and short growth-form (Milchunas et al. 1988, Augustine and McNaughton 1998). In this respect it is interesting to note that many lawn-forming grasses in Africa are halophytes (i.e. adapted to physiological drought due to high salinity) and occur in semi-dry to dry areas.

Our results suggest the existence of two stages in lawn development; patches of potentially tall bunch grass species that are kept short and attractive to grazers (caespitose lawns) and patches of short, stoloniferous grazing-tolerant lawn grass species (stoloniferous lawns). Field examples of caespitose lawns are patches of Themeda triandra that are grazed and kept short for some time period by buffalo and white rhino in Hluhluwe-iMfolozi Game Reserve (Owen-Smith 1988). Our results show that bunch grass patches that are grazed short can remain in a caespitose lawn state for a considerable period (Fig. 3A, three years) before a community shift takes place to a stoloniferous lawn. Archibald and Bond (2003) argued that a grazed patch needs to stay short for $>$ four years to be colonized by stoloniferous lawn grasses. Our results indicate that this process can be somewhat faster, because stoloniferous lawns had formed within four years after we created the short grass patches. Moreover, this community shift depended on the scale of the disturbance and only occurred in the coarser grain patches whereas in the finer grained $4 \times 4$ and $2 \times 2$ patches the vegetation remained in a caespitose lawn state. We hypothesize that the caespitose lawns are less stable than stoloniferous lawns, because the bunch growth form will directly grow back to a tall state again if grazing pressure decreases or e.g. rainfall increases while stoloniferous species will remain short for a considerable period even when grazing pressure decreases. The latter is in fact observed in exclosure experiments in HiP (Olff and W. J. Bond, unpubl.). Factors that attract grazers away from caespitose lawns might, therefore, prevent the development of more stable, stoloniferous lawns. In this respect, Archibald and Bond (2003) developed an interesting theory on the effect of fire frequency on the persistence of grazed patches and the community shift to stoloniferous grazing lawns. They hypothesize that frequent fires create a more homogenous grazing pressure and decrease the pressure on grazed patches, hereby preventing formation of stoloniferous grazing lawns.

The main driver behind lawn formation in our study was grazing in interaction with increased soil fertility. In the east African savanna systems short grasslands support dense herds of medium-sized grazers such as wildebeest, zebra and gazelles (McNaughton 1984). Owen-Smith (1988), however, suggested that only the megagrazers, white rhino and hippo, can create real permanent stoloniferous grazing lawns. He acknowledges that dense herds of e.g. wildebeest in the Serengeti transform tall grasslands into short grass but argues that their intense grazing is too temporal to induce changes in grassland composition. In our study warthog were responsible for $50 \%$ of the grazing pressure (number of observed grazing minutes) and impala 33\%. Looking at the fertilized $8 \times 8$ plots, where stoloniferous grazing lawns developed, warthog were responsible for $65 \%$ of the observed time grazed and impala for $26 \%$, while white rhino only contributed $1.5 \%$. In our study warthog and impala seemed to play an important role in maintaining caespitose lawns and promoting the colonization of stoloniferous lawn grasses. So the fact that white rhino is considered to be the main driver behind creating grazing lawns in southern Africa savannas (Owen-Smith 1988), might very well underestimate the role of the smaller grazers, like warthog. Rather, we propose that a diverse community of large and small herbivores promotes lawn formation, where megaherbivores are responsible for the first disturbance but smaller species (help) keep the grass short and promote colonization of stoloniferous grazing lawn species.

In conclusion, our results suggest that scale-dependent consumer-resource feedbacks influence the formation of local lawn-bunch mosaics. This indicates that the processes that lead to grazing lawns and the formation of lawn-bunch mosaics might indeed be described by the concept of selforganized patchiness (Rietkerk et al. 2004). This concept states that patchiness, or spatial self-organization, emerges from fine-scale consumer-resource interactions and are not imposed on the system by some existing abiotic matrix, e.g. existing soil heterogeneity. However, abiotic factors might still limit lawn grass distribution at scales above that of local grasslands. Therefore it is important to see our results as part of a nested design of mechanisms that create lawnbunch patterns, where our study gives insight in withingrassland pattern formation. On landscape scales the catena position, distance to water and variation in soil type have been argued to influence lawn formation (Bell 1971, 
McNaughton 1983a, Swemmer 1998). On an even higher regional scale potential occurrence of grazing lawns is probably determined by parent material, rainfall, herbivore geographic distributions, and possibly fire regimes (East 1984, Archibald et al. 2005).

Acknowledgements - We would first of all like to thank the many people that helped collecting the data for this study: M. te Beest, X. Mthiyane, N. Mbatha, S. Mhlongo, K. Mpanza, J. Ngubane, S. Khumalo, T. Shelembe, G. Lagendijk, J. Kusters, L. Feddema and R. Turk. Secondly we thank the management and research staff of HiP to allow us to manipulate a small part of natural savanna and for their logistic support: specifically, D. Balfour, O. Howison, S. van Rensburg, S. Nxumalo, J. Ngubane and D. Robertson. The experiment complies with the current laws in South Africa. This study has been financially supported by the Netherlands Organization for Scientific Research (WOTRO grant W84-501 and ALW PIONIER grant 833.02.001 to HO).

\section{References}

Archibald, S. and Bond, W. J. 2003. Modelling interactions between fire, rainfall and grazing. - In: Allsopp, N. et al. (eds), Proc. VIIth Int. Rangelands Congress. Durban, pp. 308-311.

Archibald, S. et al. 2005. Shaping the landscape: fire-grazer interactions in an African savanna. - Ecol. Appl. 15: 96-109.

Augustine, D. J. and McNaughton, S. J. 1998. Ungulate effects on the functional species composition of plant communities: herbivore selectivity and plant tolerance. $-\mathrm{J}$. Wildlife Manage. 62: $1165-1183$.

Bell, R. H. V. 1971. A grazing ecosystem in the Serengeti. - Sci. Am. 225: 86-94.

Cargill, S. M. and Jefferies, R. L. 1984. The effects of grazing by lesser snow geese on the vegetation of a sub-arctic salt-marsh. - J. Appl. Ecol. 21: 669-686.

Coppock, D. L. et al. 1983a. Plant-herbivore interactions in a North American mixed-grass prairie. I. Effects of black-tiled prairie dogs on intraseasonal aboveground plant biomass and nutrient dynamics and plant species diversity. - Oecologia 56: $1-9$.

Coppock, D. L. et al. 1983b. Plant-herbivore interactions in a North American mixed-grass prairie. II. Responses of bison to modification of vegetation by prairie dogs. - Oecologia 56: $10-15$.

Cromsigt, J. P. G. M. and Olff, H. 2006. Resource partitioning among savanna grazers mediated by local heterogeneity: an experimental approach. - Ecology 87: 1532-1541.

Cumming, D. H. M. and Cumming, G. S. 2003. Ungulate community structure and ecological processes: body size, hoof area and trampling in African savannas. - Oecologia 134: 560568.

Day, T. A. and Detling, J. K. 1990. Grassland patch dynamics and herbivore grazing preference following urine deposition. - Ecology 71: 180-188.

Detling, J. K. and Painter, E. L. 1983. Defoliation responses of western wheatgrass populations with diverse histories of prairie dog grazing. - Oecologia 57: 65-71.

East, R. 1984. Rainfall, soil nutrient status and biomass of large African savanna mammals. - Afr. J. Ecol. 22: 245-270.

Fryxell, J. M. et al. 2005. Landscape scale, heterogeneity, and the viability of Serengeti grazers. - Ecol. Lett. 8: 328-335.

Grant, C. C. and Scholes, M. C. 2006. The important of nutrient hot-spots in the conservation and management of large wild mammalian herbivores in semi-arid savannas. - Biol. Conserv. 130: 426-437.
Hik, D. S. and Jefferies, R. L. 1990. Increases in the net aboveground primary production of a salt-marsh forage grass-a test of the predictions of the herbivore-optimization model. - J. Ecol. 78: 180-195.

HillerisLambers, R. et al. 2001. Vegetation pattern formation in semi-arid grazing systems. - Ecology 82: 50-61.

Hobbs, N. T. and Searle, K. R. 2005. A reanalysis of the body mass scaling of trampling by large herbivores. - Oecologia 145: 462-464.

Holdo, R. M. and McDowell, L. R. 2004. Termite mounds as nutrient-rich food patches for elephants. - Biotropica 36: 231239.

Huisman, J. and Olff, H. 1998. Competition and facilitation in multispecies plant-herbivore systems of productive environments. - Ecol. Lett. 1: 25-29.

Jones, J. A. 1990. Termites, soil fertility and carbon cycling in dry tropical Africa - a hypothesis. - J. Trop. Ecol. 6: 291305.

Londo, G. 1976. The decimal scale for relevés of permanent quadrats. - Vegetatio 33: 61-64.

Manson, A. D. and Roberts, V. G. 2000. Analytical methods used by the soil fertility and analytical services section. - KZN Agrireport no. N/A/2001/04.

McNaughton, S. J. 1976. Serengeti migratory wildebeest-facilitation of energy-flow by grazing. - Science 191: 92-94.

McNaughton, S. J. 1979. Grazing as an optimization process-grass ungulate relationships in the Serengeti. - Am. Nat. 113: 691703.

McNaughton, S. J. 1983a. Serengeti grassland ecology: the role of composite environmental factors and contingency in community organization. - Ecol. Monogr. 53: 291-320.

McNaughton, S. J. 1983b. Compensatory growth as a response to herbivory. - Oikos 40: 329-336.

McNaughton, S. J. 1984. Grazing lawns: animals in herds, plant form, and coevolution. - Am. Nat. 124: 863-886.

McNaughton, S. J. et al. 1997. Promotion of the cycling of dietenhancing nutrients by African grazers. - Science 278: 17981800 .

Milchunas, D. G. et al. 1988. A generalized model of the effects of grazing by large herbivores on grassland community structure. - Am. Nat. 132: 87-106.

Mobaek, R. et al. 2005. Termitaria are focal feeding sites for large ungulates in Lake Mburo National Park, Uganda. - J. Zool. 267: 97-102.

Owen-Smith, N. 1988. Megaherbivores: the influence of very large body size on ecology. - Cambridge Univ. Press.

Owen-Smith, N. 2004. Functional heterogeneity in resources within landscapes and herbivore population dynamics. - Landscape Ecol. 19: 761-771.

Person, B. T. et al. 2003. Feedback dynamics of grazing lawns: coupling vegetation change with animal growth. - Oecologia 135: 583-592.

Rietkerk, M. et al. 2004. Self-organized patchiness and catastrophic shifts in ecosystems. - Science 305: 1926-1929.

Ritchie, M. E. and Olff, H. 1999. Spatial scaling laws yield a synthetic theory of biodiversity. - Nature 400: 557-560.

Ruess, R. W. and McNaughton, S. J. 1984. Urea as a promotive coupler of plant-herbivore interactions. - Oecologia 63: 331337.

Ruess, R. W. et al. 1983. The effects of clipping, nitrogen-source and nitrogen concentration on the growth-responses and nitrogen uptake of an east-African sedge. - Oecologia 59: 253-261.

Ruess, R. W. et al. 1997. Growth responses of Carex ramenskii to defoliation, salinity, and nitrogen availability: implications for geese-ecosystem dynamics in western Alaska. - Ecoscience 4: $170-178$. 
Swemmer, T. 1998. The distribution and ecology of grazing lawns in a South African savanna ecosystem. PhD thesis. - Univ. Cape Town.

Wang, G. M. et al. 2006. Spatial and temporal variability modify density dependence in populations of large herbivores. - Ecology 87: 95-102.
Whateley, A. and Porter, R. N. 1983. The woody vegetation communities of the Hluhluwe-Corridor-Umfolozi Game Reserve Complex. - Bothalia 14: 745-758.

Wilmshurst, J. F. et al. 1999. Spatial distribution of Serengeti wildebeest in relation to resources. - Can. J. Zool. 77: 12231232 . 